\title{
Objeto del proceso contencioso administrativo en el Perú
}

\author{
Elizabeth Roxana Mac Rae Thays
}

Abogada por la Pontificia Universidad Católica del Perú. Licenciada en Educación por la Universidad Nacional Mayor de San Marcos. Magister en Derecho Contencioso Administrativo en la Universidad de Jaén, España. Magister en Derecho Civil y Comercial por la Universidad San Martín de Porres. Profesora de la Facultad de Derecho de la Universidad de Lima.

SUMARIO:

I. Antecedentes del Proceso Contencioso Administrativo.

II. Finalidad del Proceso Contencioso Administrativo.

III. Regla de exclusividad en el Proceso Contencioso Administrativo.

IV. Actos impugnables en el Proceso Contencioso Administrativo.

1. Los actos administrativos y cualquier otra declaración administrativa.

2. El silencio administrativo, la inercia y cualquier otra omisión de la administración pública.

3. La actuación material que no se sustenta en acto administrativo.

4. La actuación material de ejecución de actos administrativos que transgrede principios o normas del ordenamiento jurídico.

5. Las actuaciones u omisiones de la administración pública respecto de la validez, eficacia, ejecución o interpretación de los contratos de la administración pública, con excepción de los casos en que es obligatorio o que se decida, conforme a ley, someter a conciliación 0 arbitraje la controversia.

6. Las actuaciones administrativas sobre el personal dependiente al servicio de la administración pública.

V. Pretensiones en el proceso contencioso administrativo.

1. Pretensión de nulidad o ineficacia.

2. Pretensión de reconocimiento o restablecimiento del derecho.

3. Pretensión de declaración como contraria a derecho y cese de una actuación material.

4. Pretensión de cumplimiento.

5. Pretensión de indemnización.

VI. Acumulación.

VII. Competencia en el proceso contencioso administrativo.

1. Competencia territorial.

2. Competencia funcional.

VIII. Conclusiones. 


\title{
RESUMEN:
}

Este artículo versará sobre el desarrollo del proceso contencioso administrativo en el Perú, comentando en parte el alcance y objetivo que este tiene como un mecanismo para proteger los derechos e intereses de los particulares frente a la Administración Pública. En parte se describirá el desarrollo histórico que ha tenido esta figura, así como las modificaciones que ha sufrido la misma desde su promulgación en el Perú.

Palabras Clave: Proceso Contencioso Administrativo, Pretensiones, Derecho Procesal Civil, Derecho Administrativo.

\begin{abstract}
:
This article discusses the development of the contentious administrative process in Peru, commenting in part on its scope and objective as a mechanism to protect the rights and interests of individuals before the Public Administration. In part, the historical development that this figure has had during the last years will be described, as well as the modifications that it has undergone since its enactment in Peru.
\end{abstract}

Keywords: Contentious Administrative Process, Claims, Civil Procedural Law, Administrative Law.

\section{ANTECEDENTES DEL PROCESO CONTENCIOSO ADMINISTRATIVO EN EL PERÚ}

La acción contencioso administrativa, como la denomina el artículo 148 de la Constitución Política de 1993, está recogida dentro de su Capítulo VIII referido al Poder Judicial. Fue incorporada como mecanismo de control jurisdiccional de la administración, con rango constitucional desde la Constitución de 1979, pero tuvieron que transcurrir más de diez años desde que se le reconociera para que contara con algunas reglas procesales específicas que permitiesen su implementación; esto fue en 1991, con la Ley Orgánica del Poder Judicial. No obstante, estas normas se derogaron en 1993, al aprobarse el Código Procesal Civil mediante Decreto Legislativo 768, de fecha 29 de febrero de 1992, y que entró en vigencia el 28 de julio de 1993, el cual reguló la impugnación de acto o resolución administrativa como proceso abreviado. El capítulo que regula el proceso contencioso administrativo fue derogado por la Ley 27584 , Ley del Proceso Contencioso Administrativo en adelante, "LPCA" - la cual entró en vigencia en el año 2002. Este proceso y sus modificaciones han sido consolidados en su Texto Único Ordenado, aprobado por Decreto Supremo №
013-2008-JUS, el cual ha sido modificado por las leyes 29782 y 29364 , así como los Decretos Legislativos 1158 y 1205.

\section{FINALIDAD DEL PROCESO CONTENCIOSO ADMINISTRATIVO}

Con la Revolución Francesa, se introducen dos principios básicos que originan el "contencioso-administrativo", el principio de legalidad de la acción de los poderes públicos y el principio de la libertad:

“(...) desde su origen las libertades públicas se configuraron como derechos subjetivos frente al Estado - derechos naturales, innatos sobre los cuales el Estado se funda y cuyo respeto y garantía constituye su fin-; estos derechos innatos imponen un ámbito de libre determinación individual completamente exento del poder del Estado: lo que los derechos individuales reclaman del Estado es, pues, una abstención"1.

Estos principios dieron origen al concepto esencial en el derecho público moderno, de "acto arbitrario" que — conforme señala GARCIA DE ENTERRIA, Eduardo, y FERNANDEZ, Tomás-Ramón" - es "el acto de un agente público que

1. GARCIA DE ENTERRIA, Eduardo, y FERNANDEZ, Tomás-Ramón. “Curso de Derecho administrativo". Tomo II. Primera Edición peruana. LIMA-BOGOTÁ: Editorial Palestra-TEMIS , 2006, p. 949.

2. GARCIA DE ENTERRIA, Eduardo, y FERNANDEZ, Tomás-Ramón. Op. Cit., pp. 549-550 
no está por su competencia o por su contenido legitimado en la Ley". Un acto arbitrario de la Administración Pública puede ser impugnado dentro de un procedimiento administrativo para ser corregido o anulado por la propia administración, de allí la exigencia del agotamiento de la vía administrativa; cuando la última instancia administrativa no lo hace, se habilita el camino para el proceso contencioso-administrativo.

El proceso contencioso administrativo tiene un doble alcance; subjetivo, al ser un mecanismo procesal para proteger los derechos e intereses de los particulares frente a la Administración Pública; y objetivo, en tanto se dirige a tutelar la legalidad de las actuaciones administrativas. Mediante este proceso se pretende la revisión de algún acto u omisión de la administración para que el juez realice un control sobre la juridicidad de esta actuación u omisión. Su objeto es amplio, encontrándose el juez facultado a no solo a declarar la nulidad del acto o declaración administrativa, sino a expedir mandatos para que se realicen las medidas necesarias para que se restablezca o reconozca la situación jurídica lesionada, aun cuando no hayan sido pretendidas en la demanda.

El proceso contencioso administrativo en la actualidad se sustenta en dos principios:

En el control judicial de los actos de la administración, según el cual la actuación de la Administración Pública debe enmarcarse dentro de lo dispuesto por la Constitución y las leyes. El ordenamiento jurídico es el límite de toda actuación administrativa, en defecto de la ley, ningún funcionario o autoridad pública podrá realizar actuaciones singulares que afecten los derechos y la esfera de libertad de los ciudadanos; es por el principio de legalidad, que se rige la administración. La revisión en sede judicial de los actos de la administración y sus omisiones se rigen por el principio de juridicidad, por el cual, en sede judicial, se verificará si los actos que realiza la administración se sujetan a la Constitución y los convenios internacionales y la interpretación que hagan de estas decisiones adoptadas por los tribunales internacionales sobre derechos humanos constituidos según tratados de los que el Perú es parte ${ }^{3}$. El ceñirse al cumplimiento de este marco es piedra angular de todo Estado democrático.

El derecho de toda a persona a una tutela judicial efectiva, en el ejercicio de sus derechos e intereses legítimos, para evitar su indefensión frente al poder la Administración Pública, implica que ningún acto de ésta podrá estar exenta de un control por parte del órgano jurisdiccional. Siendo el mecanismo ordinario que permite el control judicial de la administración pública, el proceso contencioso-administrativo se convierte en un medio de defensa del ciudadano frente a los actos, resoluciones u omisiones arbitrarias de la Administración.

Es precisamente en base a estos principios que se hizo necesario un desarrollo legislativo autónomo, que desvincule al proceso contencioso administrativo del proceso civil y que reconozca su esencia de instituto procesal para la defensa de las pretensiones o intereses de los administrados, por lo que se promulga la Ley 27584 —en adelante, "LPCA" - en el año 2001, pero que entra

3. RESOLUCIÓN DE LA CORTE INTERAMERICANA DE DERECHOS HUMANOS* DE 30 DE MAYO DE 2018 CASO BARRIOS ALTOS Y CASO LA CANTUTA VS. PERÚ EN EL FUNDAMENTO "65. La Corte recuerda que todas las autoridades de un Estado Parte en la Convención Americana, entre ellos los jueces y órganos vinculados a la administración de justicia, tienen la obligación de ejercer un "control de convencionalidad", evidentemente en el marco de sus respectivas competencias y de las regulaciones procesales correspondientes, de forma tal que la interpretación y aplicación del derecho nacional sea consistente con las obligaciones internacionales del Estado en materia de derechos humanos132. En esta tarea deben tener en cuenta no solamente la Convención Americana y demás instrumentos interamericanos, sino también la interpretación que de estos ha hecho la Corte Interamericana133. Asimismo, este Tribunal ha indicado que, en lo que respecta a la implementación de una determinada Sentencia de la Corte Interamericana, "el órgano judicial tiene la función de hacer prevalecer la Convención Americana y los fallos de esta Corte sobre la normatividad interna, interpretaciones y prácticas que obstruyan el cumplimiento de lo dispuesto en un determinado caso". 
en vigencia en el año 2002. Dicha ley lo regula autónomamente, con la finalidad de efectuar un control jurídico de las actuaciones de la Administración Pública, a cargo del Poder Judicial.

Según el Profesor Giovanni Priori, en relación a la identidad del proceso contencioso administrativo que lo distingue del proceso civil, la naturaleza de ambos procesos es distinta, precisamente por los sujetos que intervienen en el proceso y por la naturaleza de la relación de subordinación entre estos sujetos. Para lo cual recuerda que se han elaborado dos teorías, a fin de comprender esta diferencia la Teoría de la Sujeción y la Teoría del Sujeto ${ }^{4}$ que son complementarias entre sí.

La característica de la LPCA es que incorpora la tutela de plena jurisdicción, la cual se regula en función de la especial naturaleza del objeto de la pretensión, que se centra en la revisión o control judicial de los actos, omisiones y/o declaraciones administrativas de la Administración Pública. En el proceso contencioso administrativo se requiere necesariamente que una entidad estatal se constituya como una de las partes procesales del conflicto o incertidumbre jurídica cuya solución debe arribarse ante el Poder Judicial existiendo evidentemente una asimetría entre las partes en conflicto. La LPCA regula los temas propios del contencioso administrativo y deja aquellos no tratados expresamente que sean regulados de manera supletoria por el Código Procesal Civil. Esto amerita que se analice cada instituto objeto de regulación, pues el conflicto administrativo es diferente al conflicto privado, al requerir la intervención del Administración Pública antes, durante y después del proceso.

La Sala Constitucional y Social Transitoria de la Corte Suprema de Justicia de la República, en la Casación N 1684-2005 Loreto, ha establecido que la naturaleza de la plena jurisdicción del proceso regulado por la LPCA permite al juzgador tutelar los derechos del administrado apreciando tanto la actuación material no contenida en acto administrativo, como los actos administrativos expresos o fictos que deniegan la petición de cese de dicha actuación supuestamente agresiva:

\begin{abstract}
"Sexto: Que, el ejercicio de plena jurisdicción se realiza sin perjuicio de aplicar el principio de favorecimiento del proceso regulado en el artículo dos inciso tres de la Ley veintisiete mil quinientos ochenta y cuatro a fin de admitir la demanda, y cuando fuese necesario invocar tal principio en concordancia con la parte final del inciso cuarto a fin de requerir a la parte demandante alguna subsanación particular de acuerdo con las directivas del Juez".
\end{abstract}

El proceso es un instrumento para hacer efectivos derechos materiales. Por ello debe ser adecuado, oportuno y eficaz, atenuando el rigor formalista. En la jurisdicción contenciosa administrativa prima el encausamiento de oficio y el Principio de favorecimiento del proceso ${ }^{5}$, el cual nutre y otorga contenido a las reglas del

4. "La teoría de la sujeción o subordinación. Conforme a dicha teoría, mientras en los conflictos de derecho administrativo existe una desigualdad natural pues uno de los sujetos en conflicto es el Estado quien actúa en ejercicio de una función estatal como es la administrativa -en ejercicio precisamente ha surgido el conflicto de intereses o la incertidumbre jurídica que se quiere resolver - lo que determina una relación de subordinación entre los sujetos en conflicto; en los conflictos en materia civil los participantes involucrados se encuentra en un plano de igualdad jurídica, pues no existe relación de subordinación entre ellos.

La teoría del sujeto. Conforme a dicha teoría, dentro de un conflicto de naturaleza administrativa, la actividad de uno de los sujetos del conflicto se sujeta a una norma que no obliga o faculta a cualquier persona, sino necesariamente a un sujeto que es portador de la autoridad soberana —la Administración-. En los conflictos de naturaleza civil, en cambio estos surgen en virtud de actividades que pueden ser realizadas por cualquiera".

PRIORI POSADA Giovanni, "Comentarios a la Ley del Proceso Contencioso Administrativo", ARA Editores, Cuarta edición, 2009, p.97.

5. El Principio de favorecimiento de proceso - favor actionis o pro actione- está vinculado con el Principio de preferencia de los derechos fundamentales, que conforme ha establecido el Tribunal Constitucional, responde 
proceso contencioso administrativo. Por este principio, el juez debe interpretar los requisitos formales y presupuestos procesales en el sentido más favorable a la plena efectividad de la tutela jurisdiccional efectiva. Por ello, ante la duda razonable de si el proceso debe declararse concluido o no, el juez debe inclinarse por la continuidad del proceso, evitando de esta manera que el incumplimiento de formalidades tenga efectos desproporcionados o gravosos que puedan afectar la debida tutela, elemento determinante para permitir el acceso cuando, en realidad, es el instrumento procesal el que debe ser adecuado e interpretado decididamente siempre y cuando no se restrinjan los derechos constitucionales de la contraparte-, a fin de consolidar una tutela jurisdiccional más eficaz, oportuna y plena.

La ley que regula el proceso contencioso administrativo desde su promulgación ha sufrido modificaciones, además debe ser actualizada para compatibilizarla con las modificaciones realizadas por el Decreto Legislativo 1272 que modifica la Ley 27444 —Ley del Procedimiento Administrativo General y deroga la Ley 29060-
Ley del Silencio Administrativo-y con el Texto Único Ordenado de la Ley de Procedimiento Administrativo General que ha sido aprobado por Decreto Supremo $N^{\circ}$ 006-2017-JUS -en adelante, "TUO de la LPAG"-.

\section{REGLA DE EXCLUSIVIDAD DEL PROCESO CONTENCIOSO}

Es precisamente por el desarrollo histórico que ha tenido el proceso contencioso administrativo y por la naturaleza de este proceso, que expresamente se establece la regla de exclusividad del proceso contencioso administrativo como el medio procesal ordinario para la tutela de los derechos e intereses de los administrados; respecto de las actuaciones de la Administración Pública, que conlleva un litigio, autónomo y propio, diferente del que rige el Código Procesal Civil. La norma también permite, pero como regla excepcional y residual, que se puedan revisar los actos de la Administración mediante las reglas del Código Procesal Constitucional aprobado por Ley $28237^{6}$, que rige los procesos constitucionales para aquellos casos que corresponda?.

al Principio pro homine, según el cual corresponde interpretar una regla concerniente a un derecho humano "del modo más favorable para la persona, es decir, para el destinatario de la protección". Se impone a los juzgadores interpretar los requisitos y presupuestos procesales en el sentido más favorable a la plena efectividad del derecho a obtener una resolución válida sobre el fondo.

6. "Artículo 1.- Finalidad de los Procesos

Los procesos a los que se refiere el presente título tienen por finalidad proteger los derechos constitucionales, reponiendo las cosas al estado anterior a la violación o amenaza de violación de un derecho constitucional, o disponiendo el cumplimiento de un mandato legal o de un acto administrativo.

Si luego de presentada la demanda cesa la agresión o amenaza por decisión voluntaria del agresor, o si ella deviene en irreparable, el Juez, atendiendo al agravio producido, declarará fundada la demanda precisando los alcances de su decisión, disponiendo que el emplazado no vuelva a incurrir en las acciones u omisiones que motivaron la interposición de la demanda, y que si procediere de modo contrario se le aplicarán las medidas coercitivas previstas en el artículo 22 del presente Código, sin perjuicio de la responsabilidad penal que corresponda".

7. El Tribunal Constitucional mediante los fundamentos 7 y 9 de la sentencia de fecha 27 de mayo de 2013, recaìda en el proceso de amparo seguido con expediente $\mathrm{N}^{\circ} 00496-2012-\mathrm{PA} / \mathrm{TC}$, señala que tal como lo ha hecho en reiterada jurisprudencia - Expediente № 03939-2009-PA/TC, entre otras-, el proceso de amparo contra resoluciones judiciales no puede servir para replantear una controversia ya resuelta por los órganos jurisdiccionales ordinarios - la estimatoria de la excepción de caducidad y la consiguiente declaratoria de nulidad de todo lo actuado y de la conclusión del proceso contencioso-administrativo-, pues no constituye un medio impugnatorio revisor de las decisiones que sean de exclusiva competencia de la jurisdicción ordinaria y donde prima facie se han respetado las garantías del debido proceso. Por tanto, este Colegiado debe rechazar la demanda en aplicación del inciso 1) del artículo $5^{\circ}$ del Código Procesal Constitucional, el cual establece que no proceden los procesos constitucionales cuando los hechos y el petitorio de la demanda no están referidos en forma directa al contenido constitucionalmente protegido del derecho invocado. 
El Tribunal Constitucional, mediante precedentes vinculantes, ha establecido en qué casos no se afecta el contenido esencial del derecho constitucional y el justiciable debe dirigirse al proceso contencioso administrativo; y en cuáles, a la vía residual del amparo. Así tenemos que:

En la sentencia de fecha 8 de julio de 2005 recaída en el Expediente $N^{\circ}$ 01417-2005-PA/TC, Manuel Anicama Hernández, se indica que, sobre la base de los alcances del derecho fundamental a la pensión como derecho de configuración legal, se ubican las pretensiones que, por pertenecer al contenido esencial de dicho derecho fundamental o estar directamente relacionadas a él, merecen protección a través del proceso de amparo, por ello en esta sentencia se precisa lo siguiente:

a) Forman parte del contenido esencial directamente protegido por el derecho fundamental a la pensión, las disposiciones legales que establecen los requisitos del libre acceso al sistema de seguridad social, consustanciales a la actividad laboral pública o privada, dependiente o independiente, y que permite dar inicio al período de aportaciones al Sistema Nacional de Pensiones. Por tal motivo, serán objeto de protección por vía del amparo los supuestos en los que, habiendo el demandante cumplido dichos requisitos legales, se le niegue el acceso al sistema de seguridad social.

b) En segundo lugar, forma parte del contenido esencial directamente protegido por el derecho fundamental a la pensión, las disposiciones legales que establecen los requisitos para la obtención de un derecho a la pensión. Así, será objeto de protección en la vía de amparo los supuestos en los que, presentada la contingencia, se deniegue a una persona el reconocimiento de una pensión de jubilación o cesantía, a pesar de haber cumplido los requisitos legales para obtenerla -edad requerida y determinados años de aportación-, o de una pensión de invalidez, presentados los supuestos previstos en la ley que determinan su procedencia.

c) Por otra parte, forman parte de su contenido esencial aquellas pretensiones mediante las cuales se busque preservar el derecho concreto a un "mínimo vital", es decir, "aquella porción de ingresos indispensable e insustituible para atender las necesidades básicas y permitir así una subsistencia digna de la persona y de su familia; sin un ingreso adecuado a ese mínimo no es posible asumir los gastos más elementales (...) en forma tal que su ausencia atenta en forma grave y directa contra la dignidad humana" ${ }^{\prime \prime 9}$.

8. Cfr. Corte Constitucional colombiana. Sala Quinta de Revisión. Sentencia T-1001 del 9 de diciembre de 1999. M.P. José Gregorio Hernández Galindo.

9. En tal sentido, en los supuestos en los que se pretenda ventilar en sede constitucional pretensiones relacionadas no con el reconocimiento de la pensión que debe conceder el sistema previsional público o privado, sino con su específico monto, ello sólo será procedente cuando se encuentre comprometido el derecho al mínimo vital. Por ello, tomando como referente objetivo que el monto más alto de lo que en nuestro ordenamiento previsional es denominado "pensión mínima", asciende a S/. 415,00 —Disposición Transitoria de la Ley 27617 e inciso 1 de la Cuarta Disposición Transitoria de la Ley 28449_- el Tribunal Constitucional considera que, prima facie, cualquier persona que sea titular de una prestación que sea igual o superior a dicho monto, deberá acudir a la vía judicial ordinaria a efectos de dilucidar en dicha sede los cuestionamientos existentes en relación a la suma específica de la prestación que le corresponde, a menos que, a pesar de percibir una pensión o renta superior, por las objetivas circunstancias del caso, resulte urgente su verificación a efectos de evitar consecuencias irreparables — vg. los supuestos acreditados de graves estados de salud-.

“d) Asimismo, aun cuando, prima facie, las pensiones de viudez, orfandad y ascendientes, no forman parte del contenido esencial del derecho fundamental a la pensión, en la medida de que el acceso a las prestaciones pensionarias sí lo es, son susceptibles de protección a través del amparo los supuestos en los que se deniegue el otorgamiento de una pensión de sobrevivencia, a pesar de cumplir con los requisitos legales para obtenerla. 
Los alcances de la sentencia Anicama en materia previsional ha sido después ampliada y aclarada mediante la sentencia STC. № 05430 2006-PA/TC Caso Alfredo De La Cruz Curasma Amparo Previsional publicado el 10 de octubre de 2008, en el cual precisa aspectos relacionados con el pago de devengados e intereses y la STC. $\mathrm{N}^{\circ}$ 4762-2007-PA/ TC sobre la Acreditación de Aportaciones para fines Previsionales

En la sentencia de fecha 14 de noviembre de 2005 recaída en el Expediente $N^{\circ}$ 2802-2005PA/TC, Julia Mabel Benavides García, se indica que en concordancia con lo establecido por el artículo 9 del Código Procesal Constitucional ${ }^{10}$, que si existen dudas acerca de la actuación de los gobiernos locales al momento del otorgamiento o denegatoria de las licencias de funcionamiento, la parte afectada debe recurrir a la vía contencioso- administrativa, la cual cuenta con una adecuada estación probatoria. Es decir, sólo en los casos en que se sustente con claridad la afectación de un derecho fundamental, se podrá analizar el fondo de la controversia planteada en una demanda de amparo.

En la sentencia de fecha 28 de noviembre de 2005 recaída en el Expediente $N^{\circ}$ 206-2005-PA/ TC, César Antonio Baylón Flores, se indica que en virtud de la legislación laboral pública -Decreto Legislativo 276, Ley 24041 y regímenes especiales de servidores públicos sujetos a la carrera administrativa - y del proceso contencioso administrativo es posible la reposición, entonces las consecuencias que se deriven de los despidos de los servidores públicos o del personal que sin tener tal condición labora para el sector público — Ley 24041—, deberán dilucidarse en la vía contenciosa administrativa por ser la idónea, adecuada e igualmente satisfactoria, en relación al proceso de amparo, para resolver las controversias laborales públicas.

Lo mismo sucederá con las pretensiones por conflictos jurídicos individuales respecto a las actuaciones administrativas sobre el personal dependiente al servicio de la administración

e) En tanto el valor de igualdad material informa directamente el derecho fundamental a la pensión, las afectaciones al derecho a la igualdad como consecuencia del distinto tratamiento - en la ley o en la aplicación de la ley-que dicho sistema dispense a personas que se encuentran en situación idéntica o sustancialmente análoga, serán susceptibles de ser protegidos mediante el proceso de amparo, siempre que el término de comparación propuesto resulte válido. En efecto, en tanto derecho fundamental relacional, el derecho a la igualdad se encontrará afectado ante la ausencia de bases razonables, proporcionales y objetivas que justifiquen el referido tratamiento disímil en el libre acceso a prestaciones pensionarias.

f) Adicionalmente, es preciso tener en cuenta que para que quepa un pronunciamiento de mérito en los procesos de amparo, la titularidad del derecho subjetivo concreto de que se trate debe encontrarse suficientemente acreditada. $Y$ es que como se ha precisado, en el proceso de amparo "no se dilucida la titularidad de un derecho, como sucede en otros, sino sólo se restablece su ejercicio. Ello supone, como es obvio, que quien solicita tutela en esta vía mínimamente tenga que acreditar la titularidad del derecho constitucional cuyo restablecimiento invoca, en tanto que este requisito constituye un presupuesto procesal, a lo que se suma la exigencia de tener que demostrar la existencia del acto [u omisión] cuestionado". - STC 0976-2001-AA, Fundamento 3-.

g) Debido a que las disposiciones legales referidas al reajuste pensionario o a la estipulación de un concreto tope máximo a las pensiones, no se encuentran relacionadas a aspectos constitucionales directamente protegidos por el contenido esencial del derecho fundamental a la pensión, prima facie, las pretensiones relacionadas a dichos asuntos deben ser ventiladas en la vía judicial ordinaria. Las pretensiones vinculadas a la nivelación como sistema de reajuste de las pensiones o a la aplicación de la teoría de los derechos adquiridos en materia pensionaria, no son susceptibles de protección a través del amparo constitucional, no sólo porque no forman parte del contenido protegido del derecho fundamental a la pensión, sino también, y fundamentalmente, porque han sido proscritas constitucionalmente, mediante la Primera Disposición Final y el artículo $103^{\circ}$ de la Constitución, respectivamente".

10. "Artículo 9.- Ausencia de etapa probatoria

En los procesos constitucionales no existe etapa probatoria. Sólo son procedentes los medios probatorios que no requieren actuación, lo que no impide la realización de las actuaciones probatorias que el Juez considere indispensables, sin afectar la duración del proceso. En este último caso no se requerirá notificación previa". 
pública y que se derivan de derechos reconocidos por la ley, tales como nombramientos, impugnación de adjudicación de plazas, desplazamientos, reasignaciones o rotaciones, cuestionamientos relativos a remuneraciones, bonificaciones, subsidios y gratificaciones, permisos, licencias, ascensos, promociones, impugnación de procesos administrativos disciplinarios, sanciones administrativas, ceses por límite de edad, excedencia, reincorporaciones, rehabilitaciones, compensación por tiempo de servicios y cuestionamiento de la actuación de la administración con motivo de la Ley 27803 , entre otros.

Por tanto, conforme al artículo $5^{\circ}$ inciso 2) del Código Procesal Constitucional, las demandas de amparo que soliciten la reposición de los despidos producidos bajo el régimen de la legislación laboral pública y de las materias mencionadas, deberán ser declaradas improcedentes, puesto que la vía igualmente satisfactoria para ventilar este tipo de pretensiones es la contencioso administrativo. Sólo en defecto de tal posibilidad o atendiendo a la urgencia o a la demostración objetiva y fehaciente por parte del demandante de que la vía contenciosa administrativa no es la idónea, procederá el amparo. Igualmente, el proceso de amparo será la vía idónea para los casos relativos a despidos de servidores públicos cuya causa sea: su afiliación sindical o cargo sindical, por discriminación, en el caso de las mujeres por su maternidad, y por la condición de impedido físico o mental.

Es importante tener en cuenta la relevancia de los procesos contencioso administrativo en materia laboral y previsional y de revisión judicial en comparación con los otros temas, de la información de los años 2015 y 2016 cuyos cuadros de causas ingresadas en la Corte Suprema se presentan la mayor cantidad de ingresos de procesos contencioso administrativos con de temas previsionales y laborales públicos.

\section{Ingresos de PCA a la Corte Suprema en el año 2015:}

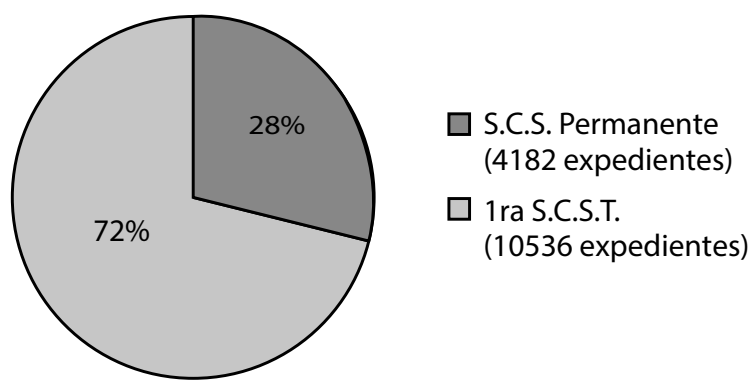

FUENTE: Servicios de Estadísticas del Centro de Investigaciones Judiciales del Poder Judicial

\section{UNIVERSO DE EXPEDIENTES}

En el $28 \%$ se incluyen:

- Procesos contencioso administrativos: 2774

- Recursos de revisión: 1408

En el $72 \%$ de procesos contencioso administrativos que, por mandato de la R.A., los procesos en materia previsional y laboral son tramitados ante la Primera Sala Constitucional y Social de la Corte Suprema.

\section{Ingresos de PCA a la Corte Suprema en el año 2017:}

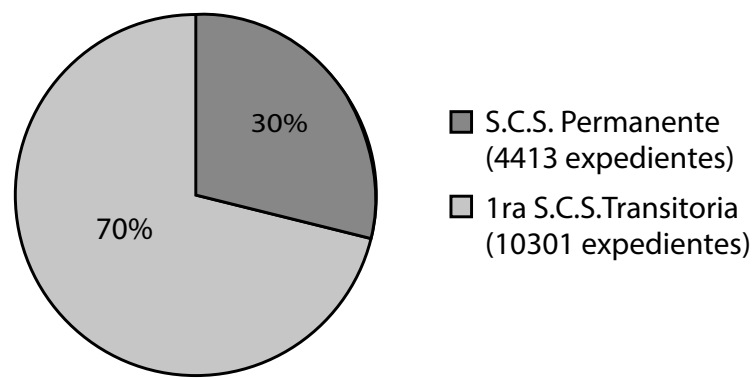

FUENTE: Servicios de Estadísticas del Centro de Investigaciones Judiciales del Poder Judicial

\section{UNIVERSO DE EXPEDIENTES}

En el $30 \%$ se incluyen:

- Procesos contencioso administrativos: 2918

- Recursos de revisión: 1495 
En el $70 \%$ de procesos contencioso administrativos que, por mandato de la R.A., los procesos en materia previsional y laboral son tramitados ante la Primera Sala Constitucional y Social de la Corte Suprema.

De allí se advierte la importancia de que el Tribunal Constitucional haya delimitado los aspectos que serán materia de proceso de amparo y del contencioso administrativo, al constituir la materia previsional y laboral público los temas de mayor conflictividad, esto se pude advertir de la estadística de ingresos de causas en lo contencioso administrativo comparativo de los años 2016 al 2018.

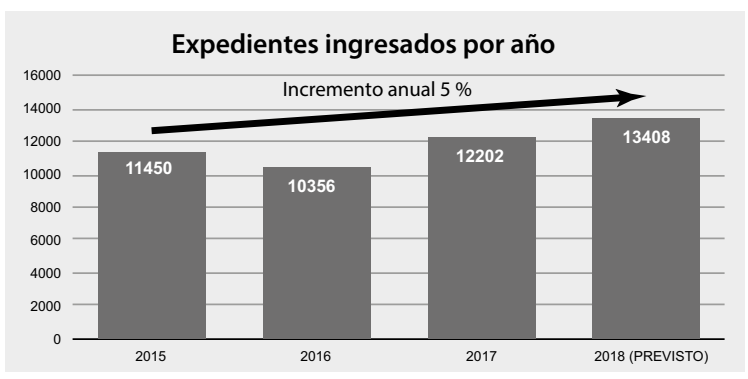

- Cada año los ingresos se incrementan en 5 $\%$, previéndose un ingreso anual de 13408 expedientes para el 2018.

- Siendo que en el año 2016 hubo una reducción debido a la huelga nacional indefinida que duro del 22 de noviembre al 30 de diciembre del 2016.

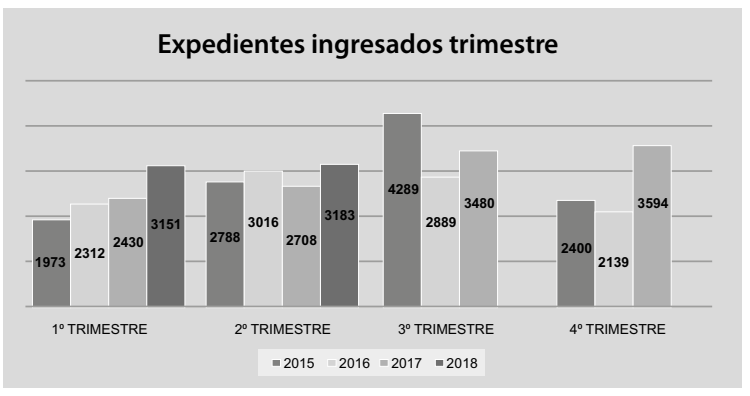

- El incremento continuo se da principalmente durante el $1^{\circ}$ y $2^{\circ}$ Trimestre de cada año, que se incrementan en $17 \%$ y $5 \%$ respectivamente.

\section{ACTOS IMPUGNABLES EN EL PROCESO CONTENCIOSO ADMINISTRATIVO}

Los actos impugnables señalados en el artículo 4 se encuentran íntimamente relacionados con las pretensiones del contencioso administrativo, las que son expresadas en el artículo 5 del TUO de la LPCA, la demanda concreta el derecho de acción; mientras que la contestación, la defensa.

El artículo 4 del TUO de la LPCA establece como actos impugnables, su relevancia está en la relación existente con la pretensión:

\section{“(...) la pretensión procesal administrativa, como acto concreto de la petición de tutela jurisdiccional, tiene como base la existencia de un "conflicto administrativo" derivado de una actuación administrativa calificada como "impugnable". Dicho motivo ha ge- nerado que las actuaciones impugnables sean catalogadas como parte del elemento objetivo de la pretensión"11.}

Los actos impugnables son:

\section{Los actos administrativos y cualquier otra declaración administrativa.}

Los actos administrativos están definidos en el artículo 1 del TUO de la LGPA, como"las declaraciones de las entidades que, en el marco de normas de derecho público, están destinadas a producir efectos jurídicos sobre los intereses, obligaciones o derechos de los administrados dentro de una situación concreta". Es importante resaltar que la norma hace referencia no solo al acto administrativo que puede estar representado en la Resolución administrativa, pero también en un oficio, memorándum y cualquier otra declaración administrativa.

\section{El silencio administrativo, la inercia y cualquier otra omisión de la administración pública.}

11. HUAPAYA TAPIA, Ramón A. "Tratado del Proceso Contencioso Administrativo". Lima: JURISTAS Editores, Primera Edición, 2006, p. 502 
En un sentido amplio el silencio administrativo agrupa el supuesto de inactividad de la administración. En un sentido restringido, el silencio administrativo es una ficción legal por la cual por el transcurso del plazo en el que la administración puede pronunciarse y de no hacerlo, se tiene por producida cierta respuesta, la que puede ser positiva - silencio positivo- o negativo - silencio negativo-.

En el caso del silencio negativo será un remedio procesal ante la inactividad procesal, se considera un beneficio a favor del administrado y no contra este, al otorgarle una facultad por la cual le corresponde a él la opción de decidir si espera o si impugna aplicando este silencio.

En el silencio positivo se genera un acto presunto, este opera en los supuestos de procedimiento de aprobación automática.

Cuando se trate de procedimientos de evaluación previa, aquellos que requieren para su aprobación de un pronunciamiento previo de la administración pública, el cual deberá ser efectuado dentro del plazo máximo de 30 días calendario de presentación de la solicitud o formulario. Estos son los procedimientos de impugnación de actos administrativos y aquellos a los cuales la ley les otorga esta calificación.

Estos procedimientos pueden ser de evaluación previa y existen dos supuestos: aquellos en los que se aplica el silencio negativo y aquellos que se aplica el silencio positivo, ejemplo el caso de licencias autorizaciones regladas.

\section{La actuación material que no se sustenta en acto administrativo.}

Las declaraciones de voluntad administrativa, que producen efectos mediante la modificación de una realidad preexistente, requieren de actuaciones denominadas materiales para su ejecución, acciones que convierten realidad lo expresado o querido por la administración en un plano formal, buscando operar en el plano meramente fáctico lo que se expresó previamente de manera formal ${ }^{12}$.

Llevar hacia los hechos la actividad formal de la administración, presupone pasar de un marco genérico de una manifestación de la denominada autotutela declarativa de la administración, es decir el ejercicio de poder de usar su propia coacción, sin necesidad de recabar el apoyo judicial. La denominada autotutela ejecutiva de la Administración supone la habilitación que el legislador otorga a la misma, para que, empleando legítimamente el uso de la coacción, ejecute o lleve a la realidad, los mandatos contenidos en las decisiones reguladoras de las relaciones jurídicas existentes entre la administración y los administrados. Esta atribución de poder coactivo a la Administración debe realizarse dentro de los márgenes de la legalidad, pero puede ocurrir que existan casos en los cuales la Administración actúe al margen de la legalidad, ejerciendo una coacción ilegitima sobre los derechos e interese de los particulares a esto se le denomina "vías de hecho"administrativas. Cuando la administración no respeta la regla según la cual esta no puede iniciar ninguna actuación material que limite derechos de los particulares sin que previamente haya adoptado la resolución que sirva de fundamento jurídico, la cual debe ser notificada antes de ordenar su ejecución material. ${ }^{13}$

\section{La actuación material de ejecución de actos administrativos que transgrede principios o normas del ordenamiento jurídico.}

Se constituye cuando la actuación material de ejecución de un acto administrativo es tan desproporcionada con el objeto o finalidad a conseguir mediante su realización, que resuelta trasgrediendo principios o normas del ordenamiento jurídico ${ }^{14}$.

12. HUAPAYA TAPIA, Ramón. Op. Cit., p. 649

13. GARCIA DE ENTERRIA Eduardo y FERNANDEZ Tomas-Ramón Op cit. Tomo II, pp. 1579-1580.

14. HUAPAYA TAPIA, Ramón. Op. cit. p. 701. 
Este supuesto implica una suerte de clausula abierta o amplia en la medida que busca abarcar el universo de actuaciones materiales que resultan de la ejecución de un acto administrativo, esto es el desarrollo de una serie de actuaciones materiales destinadas a pasar del derecho hacia los hechos. Atendiendo a esta fase de ejecución forzosa la administración tiene a su disposición cuatro medios de ejecución forzosa posibles, motivo por el cual, debe escogerse el que la ley autoriza a emplear — sea ejecución coactiva, ejecución subsidiaria, multa coercitiva, o compulsión sobre las personas-, y en caso tenga habilitada la opción de escoger entre el empleo de varios medios de ejecución coactiva, deberá escoger aquél que se amenos restrictivo de la libertad individual - conforme a la ponderación que deba realizar y respectando siempre el principio de razonabilidad- ${ }^{15}$.

\section{Las actuaciones u omisiones de la admi- nistración pública respecto de la validez, eficacia, ejecución o interpretación de los contratos de la administración pú- blica, con excepción de los casos en que es obligatorio o se decida, conforme a ley, someter a conciliación o arbitraje la controversia.}

El contrato administrativo es de naturaleza bilateral, al igual que cualquier acto administrativo tiene elementos esenciales sin los cuales carecen de validez. Estas controversias se resuelven mediante la aplicación de la Constitución Política del Perú, la norma que regula las contrataciones del Estado ${ }^{16}$ y su reglamento, así como de las normas de derecho público y las de derecho privado; manteniendo obligatoriamente este orden de preferencia en la aplicación del derecho.

Los medios de solución de controversias se regulan por el artículo 45 de la Ley 30225, Ley de Contrataciones del Estado, modificada por el Decreto Legislativo 1341 y su reglamento.
En el numeral 45.1 se establece que "Las controversias que surjan entre las partes sobre la ejecución, interpretación, resolución, inexistencia, ineficacia o invalidez del contrato se resuelven, mediante conciliación o arbitraje institucional, según el acuerdo de las partes". En el reglamento se definen los supuestos excepcionales para recurrir al arbitraje Ad Hoc. Las controversias sobre la nulidad del contrato solo pueden ser sometidas a arbitraje.

La decisión de la Entidad o de la Contraloría General de la República de aprobar o no la ejecución de prestaciones adicionales, no puede ser sometida a conciliación, ni arbitraje ni a la Junta de Resolución de Disputas. Las pretensiones referidas a enriquecimiento sin causa o indebido, pago de indemnizaciones o cualquier otra que se derive $u$ origine en la falta de aprobación de prestaciones adicionales o de la aprobación parcial de estas, por parte de la Entidad o de la Contraloría General de la República, según corresponda, no pueden ser sometidas a conciliación, arbitraje, ni a otros medios de solución de controversias establecidos en la presente Ley o el reglamento, correspondiendo en su caso, ser conocidas por el Poder Judicial. Todo pacto en contrario es nulo.

En cuanto a la impugnación del laudo arbitral el numeral 45.8 señala que este es inapelable, definitivo y obligatorio para las partes desde el momento de su notificación, debiéndose notificar a las partes en forma personal y a través del Sistema Electrónico de Contrataciones del Estado —en adelante, "SEACE" para efecto de su eficacia. La notificación se tiene por efectuada desde ocurrido el último acto. Contra dicho laudo solo cabe interponer recurso de anulación de acuerdo a lo establecido en el Decreto Legislativo 1071 Decreto Legislativo que norma el arbitraje o norma que lo sustituya.

15. HUAPAYA TAPIA, Ramón. Op. cit. p. 700.

16. La Ley 30225, Ley de Contrataciones del Estado, publicada en el Diario Oficial El Peruano el 11 de julio de 2014. La cual ha sido modificada por el Decreto Legislativo 1341, vigente desde el 03 de abril de 2017. 


\section{Las actuaciones administrativas sobre el personal dependiente al servicio de la administración pública.}

En estos procesos la controversia es entre la Administración pública y su personal, referido principalmente al personal bajo el régimen del Decreto Legislativo 276, personal que ha sido contratado que no ha sido incorporado en la carrera - Ley 24041 - o el contratado bajo el régimen del Decreto Legislativo 1057, personal CAS.

En este caso es necesario diferenciar actos administrativos con actos de Administración Interna, que no son actos administrativos puesto que afectan a las personas que forman parte de la entidad. Los actos de administración interna de las entidades organizan sus actividades o servicio, se orientan a la eficacia y eficiencia de los servicios y a los fines permanentes de las entidades. Estos actos son regulados por cada entidad, con arreglo a las disposiciones del Título Preliminar de la Ley 27444, y de aquellas normas que expresamente así lo establezcan -artículo 1 inciso 1.2.1. de la LPAG-. Pero, de acuerdo con el artículo 7 estos actos requieren ciertos requisitos para su validez, su motivación será facultativa cuando los superiores jerárquicos impartan las órdenes a sus subalternos en la forma legalmente prevista artículo 7.1.

El Dr. Napurí establece que:

"La distinción entre los actos administrativos y los actos de administración interna es evidente, estando la misma relacionada directamente con el destino de los efectos del acto. Mientras el acto de administración interna se dirige a la propia entidad, los actos administrativos se dirigen hacia fuera, vale decir, hacia el administrado. En consecuencia, una decisión administrativa que designa un comité especial constituye un acto de administración interna. Lo mismo podemos señalar respecto a una resolución administrativa que declara la baja de un bien perteneciente a la entidad. Ahora bien, el hecho de que nos encontremos ante un acto de administración interna no significa que el mismo no sea susceptible de impugnación. Ya ha señalado el Tribunal Constitucional en reiterada jurisprudencia que no existen zonas de decisión pública exentas de control jurisdiccional, lo cual es perfectamente consistente con el concepto de Estado de Derecho, en el cual las atribuciones públicas deben estar debidamente limitadas, a fin de evitar que las mismas vulneren derechos fundamentales. Ello significa que un acto de administración interna puede ser impugnado si es que vulnera derechos o intereses de una persona determinada, en aplicación de lo dispuesto por el artículo 148 de la norma constitucional que no debe considerarse restringida a los actos administrativos"17.

\section{PRETENSIONES EN EL PROCESO CONTENCIOSO ADMINISTRATIVO}

Las pretensiones del contencioso administrativo se encuentran contempladas en el artículo 5 del TUO de la LPCA:

"(...) el proceso contencioso administrativo ha sufrido un importantísimo desarrollo en su concepción pues ha pasado de un proceso en el cual sólo era posible que el órgano jurisdiccional realice una revisión de legalidad del acto, como expresión del sistema francés de "exceso de poder"18, a un proceso contencioso administrativo que brinda una efectiva tutela a las situaciones jurídicas de los justiciables, es decir, una real y efectiva tutela, la misma que va mucho más allá del solo control de legalidad del acto administrativo".

El cual establece que podrán plantearse pretensiones con el objeto de obtener lo siguiente:

17. NAPURÍ GUZMAN, Christian. "Las Actuaciones impugnables en el Proceso Contencioso Administrativo peruano". Lima: Revista del Círculo de Derecho Administrativo, p. 110.

18. PRIORI POSADA, Giovanni, Op cit, p. 129. 


\section{Pretensión de nulidad o ineficacia.}

Para establecer cuáles son los actos impugnables, cabe precisar que el artículo 3 de la LPAG establece cuáles los requisitos de validez de los actos administrativos, siendo estos: Competencia el acto administrativo debe ser emitido por el órgano facultado en razón de la materia, territorio, grado, tiempo o cuantía, a través de la autoridad regularmente nominada al momento del dictado y en caso de órganos colegiados, cumpliendo los requisitos de sesión, quórum y deliberación indispensables para su emisión. Objeto o contenido, el acto administrativo debe expresar su respectivo objeto, para que pueda determinarse inequívocamente sus efectos jurídicos. Su contenido debe ajustarse a lo dispuesto en el ordenamiento jurídico, debiendo ser lícito, posible física y jurídicamente, debe adecuarse a las finalidades de interés público asumidas por las normas que otorgan las facultades al órgano emisor, sin que pueda habilitársele a perseguir mediante el acto, aun encubiertamente, alguna finalidad sea personal de la propia autoridad, a favor de un tercero, u otra finalidad pública distinta a la prevista en la ley. Motivación, el acto administrativo debe estar debidamente motivado en proporción al contenido y conforme al ordenamiento jurídico; y antes de su emisión, el acto debe ser conformado mediante el cumplimiento del procedimiento administrativo previsto para su generación, esto es, debe ser el producto de un procedimiento regular.

"Los actos administrativos poseen elementos que lo configuran y definen su estructura, diferenciándose aquellos que resultan ser esenciales para su validez - sine qua non-, de aquellos que no son esenciales para reputar el acto como válido, pero que sin embargo pueden estar presentes en su configuración. Como resultado, un defecto o deficiencia en alguno de dichos elementos esenciales o requisitos de validez genera la nulidad del acto" ${ }^{\prime 19}$.

De acuerdo a nuestro ordenamiento todo acto administrativo se presume válido, conforme dispone el artículo 9 de la Ley 27444 —en adelante, "LPAG" —, al señalar que: "Todo acto administrativo se considera válido en tanto su pretendida nulidad no sea declarada por autoridad administrativa o jurisdiccional, según corresponda". Cuando se solicita la declaratoria judicial de nulidad, estamos frente a un acto administrativo que se presume válido, no obstante ello, la ley ha previsto un mecanismo procesal para que judicialmente se determine si se ha incumplido alguno de los presupuestos de su validez, ese medio procesal es la pretensión de nulidad, parcial o total, recogida en el artículo $5^{\circ}$ numeral 1) de la Ley 27584; para ello, el juzgador debe verificar si el acto emitido por la administración está afectado de una causal de nulidad, estas son afectaciones graves al acto administrativo que lo privan de efectos por haber contravenido el ordenamiento jurídico.

La LPAG señala expresamente en su artículo 10, que:

"Son vicios del acto administrativo, que causan su nulidad de pleno derecho:

1. La contravención a la Constitución, a las leyes o a las normas reglamentarias;

2. El defecto o la omisión de alguno de sus requisitos de validez, salvo que se presente alguno de los supuestos de conservación del acto;

3. Los actos expresos o los que resulten como consecuencia de la aprobación automática o por silencio administrativo positivo, por los que se adquiere facultades, o derechos, cuando son contrarios al ordenamiento jurídico, o cuando no se cumplen con los requisitos, documentación o tramites esenciales para su adquisición;

4. Los actos administrativos que sean constitutivos de infracción penal, o que se dicten como consecuencia de la misma.

Eljuez en cada caso verificará los supuestos de infracción de la norma para determinar caso a caso si el acto administrativo ha incurrido en alguna de las causales de nulidad".

19. NAPURÍ GUZMAN, Christian. Op. cit. p. 111. 


\section{Pretensión de reconocimiento o restablecimiento del derecho.}

Evidencia la tendencia de este proceso hacia una plena jurisdicción, pues permite que la pretensión se dirija contra cualquier actuación administrativa que vulnere los derechos o intereses subjetivos del administrado y se disponer que se adopten todas las medidas que sean necesarias para este reconocimiento y restablecimiento de la situación jurídica lesionada.

Coincidimos con lo señalado por el juez Salas ${ }^{20}$ cuando al tratar sobre esta pretensión indica que:

"El planteamiento de la pretensión de reconocimiento, como es lógico, presupone el desconocimiento o la negativa de la administración de atribuir un derecho que el administrado considera le corresponde. En otras palabras, la administración adopta una actitud que niega, refuta o rechaza un derecho o interés del administrado. Puede por ejemplo no reconocerle su derecho a registrar una marca, a ser titular de un permiso de pesca, a contar con una licencia de funcionamiento, a participar en un concurso público de proveedores, a acceder a un servicio público, a ejercer las facultades que le corresponden como titular de una concesión minera, a la devolución de un pago en exceso, al goce vacacional, al pago de la CTS o de una bonificación, etcétera. Por su lado, el planteamiento de la pretensión de restablecimiento presupone la vulneración de un derecho ya reconocido. La vulneración puede producirse, recortando, restringiendo, privando o anulando los derechos de los que gozaba un administrado. La administración en el ejercicio de sus funciones podría afectar o vulnerar indebidamente diversos derechos del administrado, así, por ejemplo, su derecho al aprovechamiento de un bien o servicio otorgado en concesión, a preservar su marca, a la regularidad o continuidad del servicio eléctrico, a la inscripción legítima de un título, al mantenimiento de una exoneración tributaria, a mantener vigente su licencia de conducir, etcétera".

\section{Pretensión de declaración como contraria a derecho y cese de una actuación material.}

Cuando la administración ha perpetrado una actuación material sin contar con el título o acto administrativo que la respalde, afectando al administrado. Se trata de una vía de hecho que quebranta el principio de legalidad.

En este caso el artículo 41 del TUO de la LPCA señala que en la sentencia estimatoria de esta pretensión el juez dispondrá:

"La cesación de la actuación material que no se sustente en acto administrativo y la adopción de cuanta medida sea necesaria para obtener la efectividad de la sentencia, sin perjuicio de poner en conocimiento del Ministerio Público el incumplimiento para el inicio del proceso penal correspondiente, y la determinación de los daños y perjuicios que resultan de dicho incumplimiento".

Evidenciando con ello el principio de tutela jurisdiccional efectiva y la facultad de plena jurisdicción al señalarse de manera amplia que el juez puede disponer toda medida que sea necesaria para hacer cesar la actuación material arbitraria e incluso para compensar por los daños y perjuicios ocasionados. Se trata de proscribir la arbitrariedad en el ejercicio de la función pública, de proteger concreta y satisfactoriamente al administrado.

\section{Pretensión de cumplimiento.}

Se plantea frente a la inactividad de la administración. Presupone la omisión o el incumplimiento de la administración de una obligación establecida por ley o por acto administrativo firme. Esta pretensión presupone que ante el incumplimiento de una obligación de la administración la autoridad jurisdiccional disponga u ordene a la administración que cumpla con su deber y realice efectivamente la actuación a la que se encuentra obligada.

20. SALAS FERRO, Percy. "Las pretensiones en el proceso contencioso administrativo". Lima: Revista Oficial del Poder Judicial: Año 6 - 7, N. ${ }^{\circ} 8$ y N. ${ }^{\circ}$ 9, Lima, 2012-2013, p. 227. 
Recogiendo el criterio establecido en la doctrina se distingue entre inactividad formal y la inactividad material. La inactividad material es la que puede ser discutida en sede judicial a través de la pretensión de cumplimiento, que se encuentra recogida en el artículo $5^{\circ}$ numeral 4) de la Ley 27584 conforme se desarrolla en el fundamento 3 de la sentencia recaída en el Expediente $\mathrm{N}^{\circ} 01716-2005-\mathrm{PC} / \mathrm{TC}$, de fecha 29 de abril de 2005, en el que el Tribunal Constitucional señaló que:

\begin{abstract}
"Mediante la acción de cumplimiento no se controla cualquier clase de inactividad, sino exclusivamente la que se ha denominado material, es decir, la que deriva del incumplimiento de mandatos nacidos de la ley o de actos administrativos, donde no media la petición de un particular, sino donde se encuentra vinculado, prima facie, un deber o el ejercicio de una atribución relacionada con sus competencias naturales. A través de la acción de cumplimiento no se controla la denominada inactividad formal de la administración, es decir, la que se origina tras el ejercicio del derecho de petición por un particular, pues esta tiene su instrumento natural de control en la técnica del silencio administrativo negativo, cuyos efectos procesales - derivados de su acogimiento- tienen el propósito de no dejar en estado de indefensión al administrado que hubiese peticionado algo o hubiese interpuesto un medio impugnatorio en el seno de un procedimiento administrativo y que, pese a ello, no hubiera recibido algún pronunciamiento expreso".
\end{abstract}

La judicatura ordinaria ha venido aplicando a la pretensión de cumplimiento prevista en el proceso contencioso administrativo, las reglas dispuestas por el Tribunal Constitucional en el precedente vinculante $\mathrm{N}^{\circ} 168-2005-\mathrm{PC} / \mathrm{TC}$ y otras, para la acción de cumplimiento que es un Proceso Constitucional, estos son entre otros: 1) que el mandato sea incondicional, 2) en caso sea condicional, que se acredite el cumplimiento de las condiciones, 3 ) que el mandato sea cierto e indubitable, 4) que tanto la ley o el acto administrativo que lo contienen deben encontrarse vigentes.

\section{Pretensión de indemnización.}

La administración en el ejercicio de sus funciones puede causar daño a los administrados, ante tal situación, el artículo 238.1 de la Ley 27444 dispone que:

"Sin perjuicio de las responsabilidades previstas en el derecho común y en las leyes especiales, las entidades son patrimonialmente responsables frente a los administrados por los daños directos e inmediatos causados por los actos de la administración o los servicios públicos directamente prestados por aquellas."

Por tanto, ha establecido la responsabilidad resarcitoria de la administración, ya que, aunque el Estado tiene la potestad de autotutela ejecutiva de sus actuaciones, ello no implica que se aparte del ordenamiento jurídico, es ahí donde se sustenta tal pretensión.

Este tema ha sido motivo de modificaciones tanto en lo sustancial como en lo procesal, mediante los Decretos Legislativos 1029 y 1067 , que configuran un régimen que restringe más las indemnizaciones atribuibles a la administración, con lo cual prácticamente las indemnizaciones han pasado al ámbito civil al considerarse que previamente se debe agotar la vía administrativa.

\section{ACUMULACIÓN}

La acumulación regulada en el TUO de la LPCA es la de pretensiones, también denominada objetiva. En este tema, cabe señalar que con el Decreto Legislativo 1067 se incorpora el Artículo 6-B, el cual establece que en el caso especial de acumulación de pretensiones sucesivas, el supuesto regulado se produce cuando, antes de la expedición de la sentencia del proceso, se produzcan nuevas actuaciones impugnables que sean consecuencia directa de aquella o aquellas que sean objeto del mismo, es posible que el demandante incorpore al proceso otra pretensión referida a una nueva actuación administrativa. Esto se da siempre que se cumplan con los requisitos de ser de competencia del mismo órgano
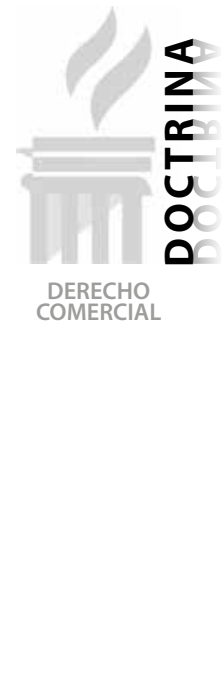
jurisdiccional; No ser contrarias entre sí, salvo que sean propuestas en forma subordinada o alternativa; Sean tramitables en una misma vía procedimental; $y$, exista conexidad entre ellas, por referirse a la misma actuación impugnable o se sustenten en los mismos hechos, o tengan elementos comunes en la causa de pedir.

El pedido de acumulación puede presentarse hasta antes de la expedición de la sentencia en primer grado, el que se resolverá previo traslado a la otra parte.

\section{COMPETENCIA EN EL PROCESO CONTENCIOSO ADMINISTRATIVO}

Las normas que regulan actualmente la competencia en el ámbito contencioso administrativo son las modificadas por el Artículo Único del Decreto Legislativo 1067, publicado el 28 de junio del 2008. Los criterios de competencia dispuesto por la LPCA son territorial y funcional.

\section{Competencia territorial.}

En cuanto a la Competencia territorial, la LPCA señala que:

"Es competente para conocer el proceso contencioso administrativo en primera instancia, a elección del demandante, el Juez en lo contencioso administrativo del lugar del domicilio del demandado o del lugar donde se produjo la actuación materia de la demanda o el silencio administrativo".

En ese sentido, establece que la administración de justicia en el ámbito del contencioso administrativo sea llevada a cabo por jueces y las salas especializadas en lo contencioso administrativo, generando una especialidad no prevista expresamente por la Ley Orgánica del Poder Judicial.

Posteriormente por Ley 29364 , se dispone que cuando se traten de pretensiones originadas en las prestaciones de servicios de carácter personal, de naturaleza laboral, administrativa o de seguridad social, de derecho público, son competentes los jueces laborales en primera instancia y Salas laborales en segunda instancia salvo excepciones que la propia Ley prevé; como consecuencia de esta competencia en materia laboral, los días 8 y 9 de mayo del 2014 se realizó el II Pleno Jurisdiccional Supremo en materia Laboral, el que se analizó la competencia en los procesos contencioso administrativos en materia de los trabajadores del Estado, dependiendo de los regímenes laborales a los cuales pertenecen ${ }^{21}$.

21. Tema № 01: Tutela procesal de los trabajadores del sector público

1.3. ¿Cuál es la vía procesal judicial pertinente para aquellos trabajadores sujetos al régimen laboral público -Decreto Legislativo 276 y los trabajadores amparados por la Ley 24041_; trabajadores que inicien y continúen su prestación de servicios suscribiendo Contratos Administrativos de Servicios —Decreto Legislativo 1057-; y, trabajadores incorporados a la carrera del servicio civil al amparo de la Ley 30057 - Ley del Servicio Civil?

El Pleno acordó por unanimidad: En aquellos distritos judiciales en los que se encuentre vigente la Ley 26636, la vía procesal será la del proceso contencioso administrativo, de conformidad con lo establecido en la Ley 27584; y, en aquellos distritos judiciales en los que se encuentre vigente la Ley 29497, Nueva Ley Procesal del Trabajo, la vía procesal será la del proceso contencioso administrativo, conforme lo establece el artículo $2^{\circ}$ numeral $4^{\circ}$ de la misma.

1.4. ¿Cuál es el órgano jurisdiccional competente para conocer demandas contencioso administrativas de aquellos trabajadores sujetos al régimen laboral público -Decreto Legislativo 276 y los trabajadores amparados por la Ley 24041-; trabajadores que inicien y continúen su prestación de servicios suscribiendo Contratos Administrativos de Servicios -Decreto Legislativo 1057-; y, trabajadores incorporados a la carrera del servicio civil al amparo de la Ley 30057 - Ley del Servicio Civil?

El Pleno acordó por unanimidad: Al amparo de la Ley 26636, el órgano jurisdiccional competente para demandas contencioso administrativas es el Juzgado Especializado de Trabajo, pues así lo estableció la Segunda Disposición Modificatoria de la Ley 29364, Ley que modifica diversos artículos del Código Procesal Civil. Mientras que, en aplicación de la Ley 29497, el órgano jurisdiccional competente para conocer las demandas contencioso 
En cuanto a la prórroga de competencia por razón de territorio en los Procesos Contenciosos Administrativos, fue tratado en el I Pleno Jurisdiccional Supremo en materias Constitucional y Contencioso Administrativa, llevado a cabo los días 2 y 10 de diciembre de 2015, preguntándose si la figura de la prórroga de la competencia resulta aplicable a algunos supuestos del proceso contencioso administrativo, al existir dos posturas asumidas por las Salas de Derecho Constitucional y Social; la primera, en el sentido que las normas que regulan el proceso contencioso administrativo son de orden público y tienen la condición de imperativas, por lo que se aplica respecto de ellas los alcances del principio de legalidad, que determina que la competencia se establece por ley. Así, si la Ley que regula el proceso contencioso administrativo no ha previsto la prórroga de competencia, entonces tal figura ha quedado descartada y no puede ser aplicada en ningún caso. La segunda, en el sentido que, si bien las normas que regulan el proceso contencioso administrativo son de orden público y tienen la condición de imperativas, ello no significa necesariamente que el sometimiento al principio de legalidad implique la proscripción de la figura de la prórroga de competencia utilizada en el proceso civil. Antes bien, a la luz de la constitucionalización del Derecho o del denominado Neoconstitucionalismo, las normas, figuras e instituciones tienen que interpretarse de la manera más proclive a la defensa de los derechos fundamentales.

Estando a las posturas señaladas, el Pleno acordó por mayoría:

"Las reglas del proceso civil sobre la prórroga
de competencia son aplicables, en lo que
resulten pertinentes, al proceso contencioso
administrativo, siempre que se trate de casos
donde se pueda poner en riesgo los derechos
fundamentales de los justiciables a la tutela
jurisdiccional que contiene el derecho de
acceso a los tribunales y para preservar sus
derechos a la igualdady al debido proceso"22.

administrativas es el juzgado especializado de trabajo, pues así se establece expresamente en el numeral 4 del artículo 2 de la Nueva Ley Procesal del Trabajo.

1.5. ¿Cuál es la vía procesal judicial para que los trabajadores demanden la invalidez del contrato administrativo de servicios?

El Pleno acordó por unanimidad:

1.5.1. Aquellos trabajadores que inicien y continúen su prestación de servicios suscribiendo Contratos Administrativos de Servicios - CAS - Decreto Legislativo 1057-, deberán tramitar su demanda de invalidez en la vía del proceso contencioso administrativo;

1.5.2. Aquellos trabajadores que iniciaron su prestación de servicios sujeto a contratos modales —Decreto Legislativo № 728- o contratos de servicios no personales - SNP-, en una entidad pública bajo el régimen laboral de la actividad privada o mixto, y que posteriormente suscribieron contratos CAS, deben tramitar su demanda de invalidez en la vía del proceso ordinario laboral;

1.5.3. Aquellos trabajadores que iniciaron su prestación de servicios sujetos a contratos temporales o contratos de servicios no personales - SNP - , en una entidad pública cuyo régimen laboral sea exclusivamente el régimen de la actividad pública, y que posteriormente suscribieron contratos CAS, deben tramitar su demanda de invalidez en la vía del proceso contencioso administrativo; $y$,

1.5.4. Si el régimen laboral de la entidad es el régimen laboral público y el trabajador inicia su prestación de servicios suscribiendo un contrato administrativo de servicios pero continúa laborando luego de vencido el plazo de vigencia del mismo, la vía procesal será la del proceso contencioso administrativo. Si el personal de la entidad se encuentra bajo el régimen laboral privado o mixto, la vía procesal será la del proceso ordinario laboral.

1.5.5. En los casos en que el juez de la causa advierta la improcedencia de la demanda por incompetencia; éste debe disponer la remisión del proceso al juez competente para que conozca del mismo o adecuar la vía procesal, de ser el caso.

22. Siendo el voto de la señora jueza suprema Rueda Fernández el siguiente: "La figura de la prórroga de la competencia no resulta aplicable al proceso contencioso administrativo, pues al estar sujeta al principio de legalidad no pueden establecerse interpretativamente supuestos de habilitación de competencia". 


\section{Competencia funcional.}

Este tema contemplado en el artículo 11 de la LPCA y se relaciona con el artículo 26 del Texto Único Ordenado de la Ley Orgánica del Poder Judicial aprobado por Decreto Supremo $\mathrm{N}^{\circ}$ 017-93-JUS ${ }^{23}$, es así que tiene competencia funcional para conocer el proceso contencioso administrativo en primera instancia el Juez Especializado en lo Contencioso Administrativo.

Cuando el objeto de la demanda verse sobre una actuación del Banco Central de Reserva, Superintendencia de Banca y Seguros y Administradoras Privadas de Fondos de Pensiones, Comisión Nacional Supervisora de Empresas y Valores, Tribunal Fiscal, Tribunal del INDECOPI, Organismo Supervisor de Contrataciones del Estado -en adelante, "OSCE"-, Consejo de Minería, Tribunal Registral, Tribunal de Servicio Civil y los denominados Tribunales de Organismos Reguladores, es competente, en primera instancia, la Sala Contencioso Administrativa de la Corte Superior respectiva. En este caso, la Sala Civil de la Corte Suprema resuelve en apelación y la Sala Constitucional y Social en casación, si fuera el caso. En los lugares donde no exista Juez o Sala especializada en lo Contencioso Administrativo, es competente el Juez en lo Civil o el Juez Mixto en su caso, o la Sala Civil correspondiente.

La ley Orgánica del Poder judicial no regula la especialidad contenciosa administrativa, ha sido por mandato de la LPCA que se "crea" la especialidad de juez en lo contencioso administrativo, por tanto, establece las funciones del juez y de la Sala. Actualmente esta especialidad no existe en todas las Cortes Superiores de allí que la norma dispone que en caso de no existir juez especializado será competente el juez especializado en lo civil. La Corte Superior de Justicia de Lima la que iniciara esta especialidad y actualmente la especialidad sobre todo en el ámbito laboral la tienen la Corte de Arequipa, Junín, Trujillo y Cuzco.

\section{CONCLUSIONES}

a) El proceso contencioso administrativo tiene un doble alcance; subjetivo, al ser un mecanismo procesal para proteger los derechos e intereses de los particulares frente a la Administración Pública y objetivo, en tanto se dirige a tutelar la legalidad de las actuaciones administrativas. Mediante este proceso se pretende la revisión de algún acto $u$ omisión de la administración para que el juez realice un control sobre la juridicidad de esta actuación u omisión. Su objeto es amplio, encontrándose el juez facultado a no solo a declarar la nulidad del acto o declaración administrativa sino a expedir mandatos para que se realicen las medidas necesarias para que se restablezca o reconozca la situación jurídica lesionada, aún cuando no haya sido pretendidas en la demanda.

b) Es precisamente por el desarrollo histórico que ha tenido el proceso contencioso administrativo y por la naturaleza de este proceso que expresamente se establece la regla de exclusividad del proceso contencioso administrativo como el medio procesal ordinario para la tutela de los derechos e intereses de los administrados, respecto de las actuaciones de la Administración Pública, que conlleva un litigio, autónomo y propio, diferente del que rige el Código Procesal Civil.

23. "Artículo 26.- Son órganos jurisdiccionales del Poder Judicial:

1.- La Corte Suprema de Justicia de la República;

2.- Las Cortes Superiores de Justicia, en los respectivos Distritos Judiciales;

3.- Los Juzgados Especializados y Mixtos, en las Provincias respectivas;

4.- Los Juzgados de Paz Letrados, en la ciudad o población de su sede; y,

5.- Los Juzgados de Paz". 
c) La Ley que regula el proceso contencioso administrativo desde su promulgación ha sufrido modificaciones además debe ser actualizada para compatibilizarla con las modificaciones realizadas por el Decreto Legislativo 1272 que modifica la Ley 27444 - Ley del Procedimiento Administrativo General y deroga la Ley 29060- Ley del Silencio Administrativo- y con el Texto Único Ordenado de la Ley de Procedimiento Administrativo General que ha sido aprobado por Decreto Supremo Nº06-2017-JUS.

d) Es importante tener en cuenta la relevancia de los procesos contencioso administrativo en materia laboral y previsional y de revisión judicial en comparación con los otros temas, de acuerdo a la información de los ingresos de procesos en casación de los años 2015 y 2016, al presentarse la mayor cantidad de ingresos de estos procesos contencioso administrativos en relación con otra problemática.

e) La ley Orgánica del Poder judicial no regula la especialidad contenciosa administrativa, ha sido por mandato de la LPCA que se "crea" la especialidad de juez en lo contencioso administrativo, por tanto, establece las funciones del juez y de la Sala. Actualmente esta especialidad no existe en todas las Cortes Superiores de allí que la norma dispone que en caso de no existir juez especializado será competente el juez especializado en lo civil. 